\title{
AKTIVITAS ANTIOKSIDAN SENYAWA FLAVONOIDA DARI DAUN BENALU KAKAO (Dendrophthoe pentandra (L.) Miq.)
}

\author{
Helmina Br. Sembiring, Sovia Lenny, Lamek Marpaung \\ Departmen Kimia, Fakultas Matematika dan Ilmu Pengetahuan Alam, Universitas Sumatera Utara, Medan \\ *Alamat Korespondensi: helmina.sembiring@usu.ac.id
}

\begin{abstract}
Abstrak: Penelitian ini bertujuan untuk mendeteksi senyawa fitokimia dan menguji aktivitas antioksidan ekstrak metanol, ekstrak etil asetat, total flavonoida dan flavonoid aglikona daun benalu kakao (Dendrophthoe pentandra (L.) Miq.). Serbuk kering daun D. pentandra (L.) Miq. (10 kg) dimaserasi dengan menggunakan metanol, ekstrak metanol diekstraksi kembali dengan etil asetat, ekstrak etil asetat dipartisi dengan $n$-heksana. Residu yang tersisa (total flavonoida) dihidrolisis dengan $\mathrm{HCl} 2 \mathrm{~N}$ sehingga diperoleh flavonoid aglikona. Diperoleh ekstrak metanol sebanyak $830 \mathrm{~g}(8,3 \%)$, ekstrak etil asetat $108 \mathrm{~g}(1,08 \%)$, total flavonoida $45 \mathrm{~g}$ $(0,06 \%)$ dan flavonoid aglikona 6,2 $\mathrm{g}(0,06 \%)$ dan semua ekstrak berwarna hitam. Berdasarkan hasil skrining fitokimia yang dilakukan ekstrak metanol D. pentandra (L.) Miq. mengandung senyawa flavonoida, tanin, terpenoid, saponin dan tidak terdeteksi adanya alkaloid. Ekstrak etil asetat mengandung senyawa flavonoida, terpenoid dan saponin dan tidak terdeteksi adanya tanin dan alkaloid. Total flavonoida hanya mengandung flavonoida dan tidak terdeteksi adanya saponin, tanin, alkaloid dan terpenoid. Ekstrak metanol, etil asetat, total flavonoida dan flavonoid aglikona daun $D$. pentandra (L.) Miq. memiliki aktivitas antioksidan dengan nilai $\mathrm{IC}_{50}$ berturut-turut sebesar 30,31; 36,23; 24,07 dan 18,22 mg/mL. Sedangkan asam askorbat sebagai kontrol menunjukkan nilai $\mathrm{IC}_{50} 12,08 \mathrm{mg} / \mathrm{mL}$. Senyawa flavonoida dari daun benalu kakao (D. pentandra (L.) Miq.) dapat berfungsi sebagai antioksidan namun aktivitasnya lebih rendah dari pada asam askorbat.
\end{abstract}

Kata kunci: flavonoid aglikona, antioksidan, Dendrophthoe pentandra (L.) Miq, fitokimia, total flavonoid

\begin{abstract}
This study aims to detect the phytochemical compounds and test the antioxidant activity of methanol extracts, ethyl acetate extracts, total flavonoids and aglycones flavonoid of cocoa parasite leaves (Dendrophthoe pentandra (L.) Miq.). Dry powder leaves D. pentandra (L.) Miq.). (10 kg ) were macerated using methanol, methanol extract re-extracted with ethyl acetate, the ethyl acetate extract was partitioned with $n$-hexane. The remaining residue (total flavonoids) was hydrolyzed with $\mathrm{HCl} 2 \mathrm{~N}$ to obtain the aglycone flavonoids. Methanol extract obtained $830 \mathrm{~g}(8.3 \%)$, the ethyl acetate extract $108 \mathrm{~g}(1.08 \%)$, total flavonoids 45 $g(0.06 \%)$ and aglycone flavonoid $6.2 \mathrm{~g}(0.06 \%)$. All extracts are black. Based on the results of phytochemical screening, methanol extract of D. pentandra (L.) Miq. contains flavonoids, tannins, terpenoids, saponins and have no alkaloids. The ethyl acetate extract contains compounds of flavonoid, terpenoid and saponins and not detected the tannins and alkaloids. Total flavonoids contain only flavonoids and have no saponins, tannins, alkaloids and terpenoids. Extract of methanol, ethyl acetate, total flavonoids and aglycone flavonoid of D. pentandra (L.) Miq.) leaves have antioxidant activity with $I C_{50}$ values respectively of $30.31 ; 36.23 ; 24.07$ and $18.22 \mathrm{mg} / \mathrm{mL}$. While ascorbic acid as a control showed the $I_{50}$ value is $12.08 \mathrm{mg} / \mathrm{mL}$. Flavonoid compounds of cocoa parasite leaves of D. pentandra (L.) Miq. have activity as antioxidant, but its activity is lower than ascorbic acid.
\end{abstract}

Keywords: aglycones flavonoid, antioxidant, Dendrophthoe pentandra (L.) Miq., phytochemicals, total flavonoids

\section{PENDAHULUAN}

Salah satu penyebab penyakit seperti kanker, peradangan, artherosclerosis maupun penuaan dini adalah spesi-spesi oksigen reaktif seperti hidrogen peroksida, superoksida, radikal hidroksil maupun senyawa radikal lainnya. Oksigen reaktif maupun senyawa radikal ini akan mengoksidasi sel-sel tubuh manusia sehingga pertumbuhan sel-sel akan terganggu, tumbuh secara tidak normal, dan akan menimbulkan penyakit (Chaterjee 2007). Untuk menangkal terjadinya oksidasi ini diperlukan suatu zat antioksidan sehingga sel-sel terlindungi dari senyawa reaktif tersebut.

Antioksidan adalah suatu senyawa yang menghambat/menunda oksidasi suatu molekul dengan cara mengakhiri reaksi berantai inisiasi dan propagasi (Molyneux, 2004). Penggunaan senyawa antioksidan sintetis seperti butil hidrositoluena (BHT) dan butil hidroksianisol (BHA) mempunyai efek samping yang bersifat karsinogenik karena dapat menyebabkan kerusakan alveolus Tipe I dan kerusakan sel endothelial paru-paru (Thompson et al. 1989). Oleh karena itu banyak perhatian dan penelitian yang tertuju kepada bahan antioksidan yang berasal dari tumbuh-tumbuhan karena aman bagi tubuh (Gupta \& Rajpurohit 2011). Menurut badan kesehatan dunia (WHO), sebanyak $80 \%$ dari total populasi di benua Asia dan Afrika bergantung pada pengobatan tradisional. WHO juga telah mengakui pengobatan tradisional dapat mengobati 
berbagai jenis penyakit infeksi, penyakit akut dan penyakit kronis (Yuningsih 2012).

Indonesia kaya akan berbagai keanekaragaman hayati yang berpotensi untuk dikembangkan sebagai obat atau bahan baku obat yang berfungsi sebagai zat antioksidan dengan sitotoksisitas yang rendah (Fazriah 2007). Penelitian terhadap tumbuhtumbuhan seperti jamu-jamuan, bumbu masakan, maupun tumbuhan yang menumpang pada tumbuhan lain, seperti benalu banyak dilakukan karena berpotensi sebagai antioksidan.

Benalu adalah tumbuhan semi-parasit, yang awalnya dianggap tumbuhan yang merugikan karena merusak tanaman komersial. Namun benalu berpotensi sebagai ramuan obat-obatan. Secara tradisional beberapa spesies benalu sejak jaman dahulu telah digunakan untuk mencegah dan mengobati berbagai penyakit antara lain sebagai obat batuk, kanker, diuretik, antiradang, antibakteri, luka atau infeksi kapang (Anita et al. 2014).

Kandungan kima yang terdapat dalam benalu adalah fenolik, tanin, asam amino, karbohidrat, alkaloid dan saponin (Jiang et al. 2001). Senyawasenyawa fenolik sangat berperan aktif sebagai antioksidan. Senyawa fenolik memiliki struktur yang dengan mudah dapat menyumbangkan hidrogen atau elektron terhadap aseptor seperti spesi oksigen reaktif atau gugus peroksil dari lemak, sehingga dapat meredam keaktifan oksigen dan radikal peroksil (Gupta \& Rajpurohit 2011).

Flavanoid adalah senyawa polifenol yang banyak ditemukan pada epidermis daun-daunan kulit buahbuahan dan memiliki peranan penting dalam kehidupan manusia sebagai antioksidan, antimutagenik, antineoplastik dan aktivitas vasodilatator (Piaru 2012). Hasil penelitian yang dilakukan oleh Artanti et al. (2003), terhadap benalu bilimbing (Macrosolen cochinchinensis) yang tumbuh pada berbagai inang menunjukkan bahwa dengan metode DPPH free radical scavenging activity, semua ekstrak air dan etanol yang diuji aktif sebagai antioksidan ( $\mathrm{IC}_{50}<50 \mu \mathrm{g} / \mathrm{mL}$ ). Simanjuntak (2003), melakukan isolasi dan identifikasi senyawa aktif antikanker dari ekstrak air benalu teh (Scurrula oortina), dan diperoleh senyawa murni katekin dan fitol dan uji sifat DPPH menunjukkan $\mathrm{IC}_{50}$ berturutturut sebesar 82,4 ppm dan 88,77 ppm.

Dendrophthoe pentandra (L.) Miq. adalah salah satu benalu yang tumbuh pada pohon kakao yang banyak dijumpai pada perkebunan kakao di Desa Jandi Kecamatan Tiga Binanga, Sumatera Utara. Benalu ini sangat merugikan para petani kakao, karena merusak tanaman komersial mereka. Benalu ini dibuang begitu saja tidak dipergunakan sebagi ramuan obat-obatan oleh masyarakat, karena ketidaktahuan masyarakat akan khasiat benalu ini. Siahaan et al. (2015) telah melakukan penelitian pendahuluan akan kandungan senyawa metabolit sekunder dan uji aktivitas antioksidan terhadap daun benalu ini. Menurut Runyon et al. (2009), struktur benalu dan fungsinya berbeda jika inangnya berbeda. Hal ini disebabkan karena benalu tersebut mengambil nutrien dan senyawa pertahanan diri dari tumbuhan inang tempat tumbuhnya untuk menjaga kelangsungan hidup dan mencegah pendeteksian hewan herbivora (Adler 2002).

Penelitian ini bertujuan untuk melakukan isolasi, dan uji aktivitas antioksidan terhadap senyawa flavonoida yang diperoleh dari daun benalu kakao. Untuk memperoleh senyawa flavonoida tersebut serbuk daun benalu terlebih dahulu diekstraksi dengan metanol, kemudian ekstrak metanol kering diekstraksi kembali dengan etil asetat dan ekstrak etil asetat dipartisi dengan $n$-heksana. Residu yang tidak larut dengan $n$-heksana merupakan total flavonoida. Total flavonoida dihidrolisis dengan $\mathrm{HCl} 2 \mathrm{~N}$ untuk mendapatkan flavonoid aglikona. Ekstrak metanol, etil asetat dan ekstrak $n$-heksana diskrining fitokimia untuk mengetahui golongan senyawa metabolit yang terdapat didalamnya, dan dilakukan uji aktivitas antioksidan terhadap ketiga ekstrak tersebut beserta total flavonoid dan flavonoid aglikon untuk mengetahui aktivitasnya sebagai zat antioksidan. Uji aktivitas antioksidan dilakukan dengan menggunakan 1,1-diphenyl-2picryl-hydrazil (a,a-diphenyl-bpicrylhidrazyl) atau metode DPPH radicalscavenging.

\section{BAHAN DAN METODE Pengadaan Sampel}

Daun benalu kakao dikoleksi dari perkebunan kakao Desa Jandi Kabupaten Karo Sumatera Utara, dan diidentifikasi di Laboratorium Herbarium Bogoriense bidang botani Pusat Penelitian Biologi LIPI Cibinong. Berdasarkan hasil identifikasi yang dilakukan tumbuhan benalu kakao yang digunakan dalam penelitian ini adalah D. pentandra (L.) Miq famili Loranthaceae.

\section{Ekstraksi}

Ekstraksi dilakukan berdasarkan Sarker (2006). Daun benalu dihaluskan, ditimbang sebanyak $10 \mathrm{~kg}$, dimaserasi dengan pelarut metanol selama 24 jam, kemudian diekstraksi sehingga diperoleh maserat. Maserasi dilakukan beberapa kali hingga maserat yang diperoleh sudah tidak mengandung senyawa flavonoida. Filtrat hasil maserasi diuapkan pelarutnya sehingga diperoleh ekstrak metanol, terhadap ekstrak ini ditambahkan etil asetat, disaring. Filtrat yang diperoleh diuapkan pelarutnya sehingga diperoleh ekstrak etil asetat. Kemudian ekstrak etil asetat dilarutkan dalam metanol, dipartisi dengan $n$ heksana. Lapisan bawah (fraksi metanol) diambil, diuapkan kembali sehingga diperoleh total flavonoida. Kemudian total flavonoida dihidrolisis dengan $\mathrm{HCl} 2 \mathrm{~N}$ dan disaring. Filtrat dipartisi dengan kloroform. Fraksi kloroform diambil dan diuapkan sehingga diperoleh flavonoid aglikon. 


\section{Skrining Fitokimia}

Alkaloida

Ekstrak metanol, etil asetat dan total flavonoida dari daun D. pentandra (L.) Miq. masing-masing dimasukkan dalam 4 tabung reaksi. Tabung I ditetesi pereaksi Wagner, tabung II ditetesi pereaksi Maeyer, tabung III ditetesi pereaksi Bouchardat, tabung IV ditetesi pereaksi Dragendorf.

\section{Flavonoida}

Ekstrak metanol, etil asetat dan total flavonoida dari daun D. pentandra (L.) Miq. masing-masing dimasukkan dalam 2 tabung reaksi. Tabung I ditetesi $\mathrm{NaOH} 10 \%$, tabung II ditambah serbuk $\mathrm{Mg}$ dan $\mathrm{HCl}$ pekat.

\section{Tanin}

Ekstrak metanol, etil asetat dan total flavonoida dari daun D. pentandra (L.) Miq. masing-masing dimasukkan dalam tabung reaksi, kemudian ditambah dengan $\mathrm{FeCl}_{3} 5 \%$.

\section{Terpenoida}

Ekstrak metanol, etil asetat dan total flavonoida dari daun D. pentandra (L.) Miq. masing-masing dimasukkan dalam tabung reaksi kemudian ditambah dengan $\mathrm{CeSO}_{4} 1 \%$ dalam $\mathrm{H}_{2} \mathrm{SO}_{4} 10 \%$.

\section{Saponin}

Ekstrak metanol, etil asetata dan total flavonoida dari daun Dendrophthoe pentandra (L.) Miq. masingmasing ditambah $10 \mathrm{ml}$ aquades, kemudian dikocok kuat-kuat (Vaishali 2013).

\section{Uji Aktivitas Antioksidan}

Dibuat variasi konsentrasi larutan ekstrak metanol dengan terlebih dahulu dibuat larutan induk 1000 $\mathrm{mg} / \mathrm{mL}$ yaitu dengan melarutkan $10 \mathrm{mg}$ ekstrak metanol kedalam metanol p.a dalam labu takar 100 $\mathrm{mL}$. Kemudian dari larutan induk dibuat variasi konsentrasi larutan 10, 20, 30 dan $40 \mathrm{mg} / \mathrm{mL}$. Selanjutnya dibuat larutan DPPH $0,3 \mathrm{mM}$ dengan melarutkan 11,83 mg serbuk DPPH (BM 394,32) dalam metanol p.a pada labu takar $100 \mathrm{~mL}$ dan ditutup dengan aluminum foil dan sebanyak $1 \mathrm{~mL}$ larutan DPPH 0,3 mM ditambahkan ke dalam larutan ekstrak metanol 2,5 mL dalam tabung reaksi (yang ditutup dengan aluminum foil), kemudian dihomogenkan dan diinkubasi selama 30 menit pada suhu $37^{\circ} \mathrm{C}$. Kemudian diukur absorbansi dengan panjang gelombang maksimum $515 \mathrm{~nm}$. Sebagai pembanding digunakan asam askorbat. Prosedur yang sama dilakukan terhadap ekstrak etil asetat, ekstrak $n$-heksana, total flavonoida dan flavonoid aglikon.

\section{HASIL DAN PEMBAHASAN \\ Ekstraksi dan Skrining Fitokimia Daun $D$. pentandra (L.) Miq.}

Senyawa flavonoida diekstraksi dari daun benalu kakao dengan menggunakan pelarut metanol. Dari sebanyak $10 \mathrm{~kg}$ serbuk daun D. pentandra (L.) Miq. (Gambar 1) diperoleh ekstrak metanol berwarna hitam sebanyak $830 \mathrm{~g}(8,5 \%)$. Ekstrak metanol diekstraksi kembali dengan pelarut etil asetat dan diperoleh ekstrak etil asetat berwarna hitam sebanyak $108 \mathrm{~g}$ (1,08\% terhadap berat serbuk daun benalu). Ekstrak etil asetat dilarutkan dengan metanol dan dipartisi kembali dengan pelarut $n$-heksana berkalikali hingga filtrat $n$-heksana jernih dan diperoleh total flavonoida sebanyak $45 \mathrm{~g}(0,45 \%)$.

Total flavonoida yang diperoleh dihidrolisis dengan $\mathrm{HCl} 2 \mathrm{~N}$ dan diperoleh ekstrak kloroform sebanyak $6,2 \mathrm{~g}(0,06 \%)$ yang merupakan flavonoid aglikona. Ekstrak yang diperoleh dapat ditabulasikan pada Tabel 1 .

Ekstrak metanol, etil asetat dan total flavonoid dari daun $D$. pentandra (L.) Miq. yang diperoleh diuji skrining fitokimia untuk mengetahui adanya golongan senyawa alkaloida, flavonoida, tanin dan saponin. Hasil skrining yang dilakukan ditunjukkan pada Tabel 2. Berdasarkan skrining fitokimia yang dilakukan, ekstrak metanol dan etil asetat daun $D$. pentandra (L.) Miq. Mengandung flavonoid, saponin dan terpenoid. Ekstrak metanol mengandung tanin namun ekstrak etil asetat tidak mengandung tanin. Pada penambahan $\mathrm{FeCl}_{3} 5 \%$ ekstrak etil asetat dan

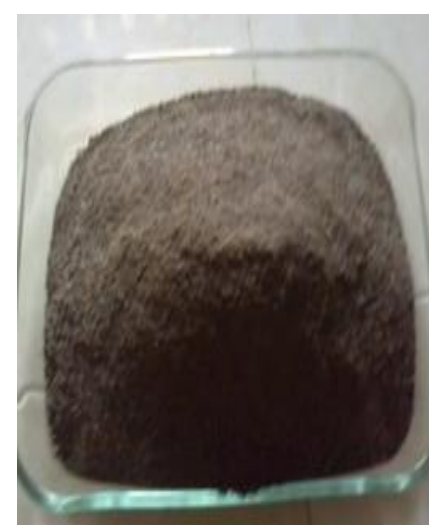

(A)

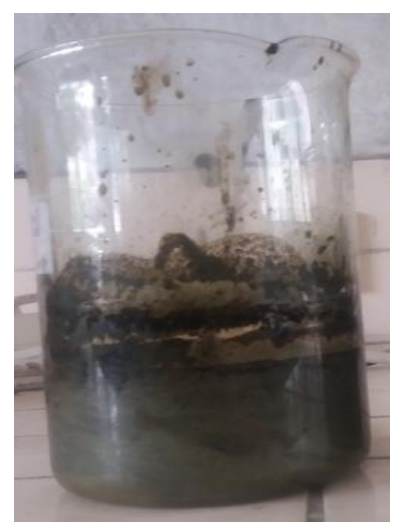

(B)

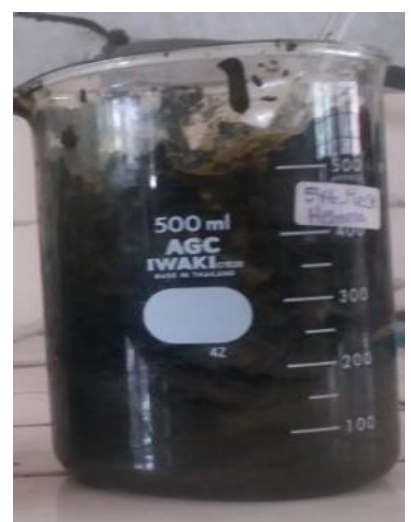

(C)

Gambar 1. (A) Serbuk; (B) Ekstrak methanol; (C) Ekstrak etil asetat daun D. pentandra (L.) Miq. 
Tabel 1. Bobot dan kadar hasil ekstraksi daun benalu kakao (D.pentandra (L.)Mig).

\begin{tabular}{lcc}
\hline \multicolumn{1}{c}{ Hasil ekstraksi } & Bobot $(\mathrm{g})$ & Kadar $(\%)$ \\
\hline Ekstrak metanol (hitam) & 830 & 8,5 \\
Ekstrak etil asetat (hitam) & 108 & 1,08 \\
Total flavonoida (hitam) & 45 & 0,45 \\
Flavonoid aglikona (hitam) & 6,2 & 0,06 \\
\hline
\end{tabular}

Tabel 2. Hasil skrining Fitokimia Ekstrak Metanol (EM), Etil Asetat (EE), $n$-heksana (EH) dan total flavonoida (TF) dari daun D. pentandra (L.) Miq.

\begin{tabular}{|c|c|c|c|c|}
\hline \multirow[t]{2}{*}{ Parameter } & \multirow[t]{2}{*}{ Pereaksi } & \multicolumn{3}{|c|}{ Sampel } \\
\hline & & EM & $\mathrm{EE}$ & $\mathrm{TF}$ \\
\hline \multirow[t]{4}{*}{ Alkaloida } & Dragendorf & - & - & - \\
\hline & Bouchardat & - & - & - \\
\hline & Maeyer & - & - & - \\
\hline & Wagner & - & - & - \\
\hline \multirow[t]{2}{*}{ Flavonoida } & $\mathrm{NaOH} 10 \%$ & + & + & + \\
\hline & $\mathrm{Mg}$ dan $\mathrm{HCl}$ pekat & + & + & + \\
\hline Tanin & $\mathrm{FeCl}_{3} 5 \%$ & + & $+^{*}$ & $+^{*}$ \\
\hline Terpenoida & $\mathrm{CeSO}_{4} 1 \%$ dalam $\mathrm{H}_{2} \mathrm{SO}_{4} 10 \%$ & + & + & - \\
\hline Saponin & Aquadest & + & + & - \\
\hline
\end{tabular}

total flavonoida memberikan warna hitam, namun bukan karena adanya tanin karena tanin umumnya tidak larut dalam pelarut etil asetat. Sedangkan dalam total flavonoida yang terdeteksi hanyalah flavonoida dan tidak terdeteksi adanya saponin, tanin, terpenoid dan alkaloid sehingga disebut total flavonoida.

\section{Aktivitas Antioksidan}

Aktivitas antioksidan ekstrak metanol, ekstrak etil asetat, total flavonoida dan flavonoid aglikona diuji berdasarkan metode penangkapan radikal bebas DPPH (1,1-difenil-2-pikrilhidrazil) menggunakan spektroskopi UV - Visible pada panjang gelombang maksimum $515 \mathrm{~nm}$, dengan menggunakan asam askorbat sebagai pembanding. Berdasarkan nilai absorbansi yang diperoleh dapat dihitung persentase peredaman radikal bebas DPPH oleh keempat sampel berdasarkan persamaan (1).

Persentase Peredaman $=\left(\frac{\text { Abs blanko }- \text { Abs sampel }}{\text { Abs blanko }}\right) \times 100 \%$

Absorbansi dan persentase peredaman ekstrak metanol, ekstrak etil asetat, total flavonoida, flavonoid aglikona dan asam askorbat dapat dilihat dalam Tabel 3. Aktivitas antioksidan dinyatakan dengan nilai $\mathrm{IC}_{50}$ dan diperoleh dari persamaan garis regresi, dengan konsentrasi sebagai variabel bebas dan persentase peredaman sebagai variabel terikat. Persamaan regresi dan nilai $\mathrm{IC}_{50}$ ekstrak metanol, ekstrak etil asetat, total flavonoida flavonoid aglikona dan asam askorbat sebagai pembanding dapat dilihat dalam Tabel 4. Dari Tabel 3 dan 4 terlihat bahwa keempat sampel di atas memiliki aktivitas sebagai penangkap radikal bebas DPPH. Semakin tinggi konsentrasi sampel maka persentase peredaman semakin besar, dan semakin berkurang konsentrasi DPPH. Hal ini disebabkan karena radikal bebas DPPH mengabstraksi radikal hidrogen dari senyawa antioksidan dan membentuk DPPHH (1,1-difenil-2pikrilhidrazin). Berkurangnya radikal bebas ini juga ditandai dengan perubahan warna larutan dari ungu menjadi kuning pucat. Semakin tinggi persentase peredaman menunjukkan sampel tersebut memiliki aktivitas antioksidan yang semakin kuat. Konsentrasi suatu zat antioksidan yang dibutuhkan untuk meredam 50\% radikal bebas DPPH pada waktu tertentu (15 - 30 menit) disebut sebagai $\mathrm{IC}_{50}$ (Seifu et al. 2012). Aktivitas antioksidan dinyatakan dengan nilai $\mathrm{IC}_{50}$ dan diperoleh dari persamaan regresi, dengan konsentrasi sebagai variabel bebas dan persentase peredaman sebagai variabel terikat. Persamaan regresi dan nilai $\mathrm{IC}_{50}$ ekstrak metanol, 
Tabel 3. Absorbansi dan persentase peredaman ekstrak metanol (EM), ekstrak etil asetat (EE), total flavonoida (TF), flavonoid aglikona (AF) dan asam askorbat (AA).

\begin{tabular}{|c|c|c|c|c|c|c|c|c|c|c|}
\hline \multirow{2}{*}{$\begin{array}{l}\text { Konsentrasi } \\
(\mu \mathrm{g} / \mathrm{ml})\end{array}$} & \multicolumn{5}{|c|}{ Absorbansi } & \multicolumn{5}{|c|}{ Persentase Peredaman (\%) } \\
\hline & EM & $\mathrm{EE}$ & $\mathrm{TF}$ & $\mathrm{AF}$ & AA & EM & $\mathrm{EE}$ & $\mathrm{TF}$ & $\mathrm{AF}$ & $\mathrm{AA}$ \\
\hline 0 & 0.78 & 0.78 & 0.78 & 0.78 & 0.78 & 0 & 0 & 0 & 0 & 0 \\
\hline 10 & 0.64 & 0.65 & 0.65 & 0.64 & 0,42 & 17,95 & 16,66 & 17,94 & 18,66 & 48,15 \\
\hline 20 & 0.23 & 0.58 & 0.34 & 0.47 & 0,16 & 60,51 & 25,64 & 39,74 & 71,41 & 88,49 \\
\hline 30 & 0.15 & 0.45 & 0.15 & 0.20 & 0,02 & 68.77 & 42.31 & 74.36 & 88.77 & 97.83 \\
\hline 40 & 0.04 & 0.35 & 0.10 & 0.19 & * & 79.87 & 55.13 & 75.64 & 94.18 & $*$ \\
\hline
\end{tabular}

Tabel 4. Persamaan garis regresi dan nilai $\mathrm{IC}_{50}$ ekstrak metanol, ekstrak etil asetat, total flavonoida, flavonoid aglikona dan asam askorbat.

\begin{tabular}{lcc}
\hline \multicolumn{1}{c}{ Sampel } & Persamaan garis regresi & Nilai $^{1} \mathrm{IC}_{50}(\mu \mathrm{g} / \mathrm{ml})$ \\
\hline Ekstrak metanol & $\mathrm{Y}=2,488 \mathrm{x}-25,41$ & 30,31 \\
Ekstrak etil asetat & $\mathrm{Y}=1,359 \mathrm{x}+0,77$ & 36,23 \\
Total flavonoida & $\mathrm{Y}=2,077 \mathrm{x}-0,00$ & 24,07 \\
Flavonoid aglikona & $\mathrm{Y}=2,584 \mathrm{x}+2,91$ & 18,22 \\
Asam askorbat & $\mathrm{Y}=3,34 \mathrm{x}+8,54$ & 12,26 \\
\hline
\end{tabular}

Gambar 2. Penangkapan radikal bebas DPPH oleh senyawa fenolik

ekstrak etil asetat, total flavonoid, flavonoid aglikona dan asam askorbat sebagai pembanding dapat dilihat dalam Tabel 4.

Dari Tabel 4 terlihat flavonoid aglikona memiliki nilai $\mathrm{IC}_{50}$ yang paling kecil dibandingkan dengan ketiga sampel lainnya. Ini menunjukkan flavonoid aglikona memiliki aktivitas antioksidan yang paling tinggi. Hal ini disebabkan karena flavonoid aglikona merupakan senyawa fenolik yang memiliki gugus hidroksi yang mudah mendonorkan radikal hidrogen terhadap radikal, dan memiliki sistim aromatik terkonjugasi yang dapat mengalami delokalisasi elektron tak berpasangan (Dai \& Russell 2010). Demikian juga memiliki ikatan rangkap $\Delta^{2,3}$ yang berkonjugasi dengan gugus 4-keto pada cincin C, sangat aktif sebagai pendelokalisasi elektron dari cincin B, dan akan meningkatkan kapasitasnya sebagai penangkap radikal. Demikian juga dengan adanya gugus 3-hidroksil pada cincin $\mathrm{C}$ yang bergabung dengan gugus 4-keto dan ikatan rangkap $\Delta^{2,3}$ juga akan meningkatkan aktivitas sebagai penangkap radikal bebas (Seifu et al. 2012). Namun demikian flavonoid aglikona ini memiliki aktivitas antioksidan yang lebih rendah dari pada asam askorbat sebagai pembanding. Aktivitas antioksidan ekstrak metanol lebih kuat dari pada ekstrak etil asetat. Hal ini kemungkinan disebabkan karena dalam ekstrak metanol terdapat senyawa-senyawa flavonoid seperti flavan-3-ol (seperti katekhin dan proantosianidin) yang tidak terdapat dalam ekstrak etil asetat karena sifatnya lebih polar sehingga ketika diekstraksi dengan etil asetat flavonoid tersebut tertinggal pada residu bersama dengan tannin (Andersen 2006) dan ada kalanya tannin seperti Cglukosidik ellagitanin lebih efektif sebagai zat antioksidan dari pada senyawa flavonoida (Yoshimura et al. 2008; Jun et al. 2006). Penangkapan radikal bebas DPPH oleh senyawa fenolik ditunjukkan dalam Gambar 2 (Seifu et al. 2012).

\section{KESIMPULAN}

Sebanyak $10 \mathrm{~kg}$ serbuk kering daun benalu kakao D. pentandra (L.) Miq. diekstraksi secara maserasi diperoleh ekstrak methanol $830 \mathrm{~g}(8,3 \%)$, ekstrak etil asetat $108 \mathrm{~g}(1,08 \%)$, total flavonoida $45 \mathrm{~g}(0,06 \%)$ dan flavonoid aglikona $6,2 \mathrm{~g}(0,06 \%)$ dan berwarna hitam. Berdasarkan hasil skrining fitokimia yang dilakukan ekstrak metanol D. pentandra (L.) Miq. mengandung senyawa flavonoid, tanin, terpenoid, 
saponin dan tidak terdeteksi adanya alkaloid, ekstrak etil asetat mengandung senyawa flavonoida, terpenoida dan saponin dan tidak terdeteksi adanya tannin dan alkaloid, total flavonoida hanya mengandudng flavonoida dan tidak terdeteksi adanya saponin, tannin, alkaloid dan terpenoid. Ekstrak metanol, etil asetat, total flavonoida dan flavonoid aglikona daun $D$. pentandra (L.) Miq. memiliki aktivitas antioksidan dengan nilai $\mathrm{IC}_{50}$ berturut-turut sebesar 30,31; 36,23; 24,07 dan 18,22 $\mu \mathrm{g} / \mathrm{mL}$. Sedangkan asam askorbat sebagai kontrol menunjukkan nilai $\mathrm{IC}_{50} 12,08 \mu \mathrm{g} / \mathrm{mL}$. Senyawa flavonoida dari daun benalu kakao (D. pentandra (L.) Miq) dapat berfungsi sebagai antioksidan namun aktivitasnya lebih rendah dari pada asam askorbat.

\section{DAFTAR PUSTAKA}

Adler, L.S. (2002). Host Effect on Herbivora and Pollination in a Hemiparasitic Plant. Ecology. 83(10): $2700-2710$.

Andersen, Q.M. \& Markhan, K.R. (2006). Flavonoids Chemistry, Biochemistry and Aplications. Boca Raton: Taylor and Francis.

Anita, A., Khotimah, S. \& Yanti, A.H. (2014). Aktivitas Antibakteri Ekstrak Daun Benalu Jambu Air (Dendrophthoe pentandra (L.) Miq Terhadap Pertumbuhan Salmonela typhi. Protobiont. 3(2): $266-272$.

Artanti, N., Jamilah, dan Hartati, S., 2003, Laporan Teknis Sub Tolok Ukur Pengembangan Senyawa Potensial antikanker dari Taxus sumatrana dan Benalu, Puslit Kimia LIPI, Serpong.

Chatterjee, S., Niaz, Z., Gautam, S., Adhikari, S., Variyar, P.S. \& Sharma, A. (2007). Antioxidant Activity of some phenolic constituents from green pepper (Piper ningrum L.) and Fresh nutmeg mace (Myristica fragrans). Food Chemistry. 101: $515-523$.

Dai, J. \& Mumper, R.J. (2010). Plant phenolics: extraction, analisis and their antioksidant and anticancer properties. Molecules. 15(10): 7313 -7352 .

Fajriah, S., Darmawan, A., Sundowo, A. \& Artanti, N. (2007). Isolasi senyawa antioksidan dari ekstrak etil asetat daun benalu Dendrophthoe pentandra L. Mig yang tumbuh pada inang lobi-lobi. Jurnal Kimia Indonesia. 2(1): 17-20.

Gupta, A.D. \& Rajpurohit, D. (2011). Antioxidant and Antimicrobial Activity of Nutmeg (Myristica fragrans). In Preedy, V.R., Watson, R.R. \& Patel, V.B. (eds). Nuts and Seeds in Health and Disease Prevention. Page 831 838.

Jiang, Z-H., Tanaka, T., Sakamoto, M., Jiang, T. \& Kouno, I. (2001). Studies on Medicinal Plant: Lignans from the Stems of Cynomorium songaricum. Chemical and Pharmaceutical Bulletin. 49(8): 1036 - 1038.
Jun, M., Fu, H.-Y., Hong, J., Wan, X., Yang, C.S. \& Ho, C.-T. (2003). Comparison of antioxidant activity of isoflavones from kudzu root (Pueraria lobata Ohwi). Journal of Food Science. 68(6): $2117-2122$.

Molyneux P. (2004). The use of the stable free radical diphenylpicrylhydrazyl (DPPH) for estimating antioxidant activity. Songklanakarin Journal of Science and Technology. 26: 211 219.

Runyon, J. B., Tooker, J.F., Mescher, M.C \& De Moraes, C.M. (2009). Parasitic Plants in Agriculture: Chemical Ecology of Germination and Host-Plant Location as Targets for Sustainable Control: A Review. In De Moraes, C.M. (ed). Organic Farming, Pest Control and Remediation of Soil Pollutants. Pp. 123 - 136.

Piaru, S.P., Mahmud, R., Majid, A.M.S.A. \& Nassar, Z.D.M. (2012). Antioxidant and antiangiogenic activities of the essential oils of Miristica fragrans and Morinda citrifolia. Asian Pacific Journal of Tropical Medicine. 5(4): 294 - 298.

Sarker, S.D. \& Latif, Z. (2006). Alexander I. Gray Natural Products Isolation. New Jersey: Human Press.

Seifu,D., Assefa, F. \& Abay, S.M. (2012). Medicinal plants as antioxidant agent: understanding their mechanism of action and therapeutic efficacy. In Capasso, A. (ed). Medicinal Plants as Antioxidant Agents: Understanding Their Mechanism of Action and Therapeutic Efficacy. Pp. $97-145$.

Siahaan, C.E., Sembiring, H.Br., Sihotang, H. (2015). Uji skrining fitokimia, aktivitas antioksidan dan antibakteri ekstrak methanol, etil asetat dan $n$ heksana daun benalu kakao (Dendrophthoe pentandra (L.) Mig.). Skripsi. Medan: Depertemen Kimia FMIPA USU.

Simanjuntak, P. \& Murwani, R. (2003). Isolasi dan Identifikasi Senyawa Aktif Antitumor dari Ekstrak Air Benalu Teh Scurrula oortiana. Laporan Akhir Penelitian Hibah Bersaing. Lembaga Penelitian Universitas Diponegoro.

Thomson, D.C., Cha, T.N. \& Trush, M.A. (1989). The peroxidase-dependent activation of butylated hydroxyanisole and butylated hydroxytoluene (BHT) to reactive intermediates formation of BHT-quinone methide via a chemical-chemical interaction. Journal of Biological Chemistry. 264(7): 3957-3965.

Yoshimura, M., Ito, H., Miyashita, K., Hatano, T., Taniguchi, S., Amakura, Y. \& Yoshida, T. (2008). Flavonol glucuronides and C-glucosdic elladitannins from Melaleuca squarrosa. Phytochemistry. 69(18): 3062-3069.

Yuningsih, R. (2012). Pengobatan Tradisional di Unit Pelayanan Kesehatan. Info Singkat Kesejahteraan Sosial. 4(5): 9-12. 